Article

\title{
The Effect of Stock Return Sequences on Trading Volumes
}

\section{Andrey Kudryavtsev}

Economics and Management Department, The Max Stern Yezreel Valley College, P.O. Emek Yezreel, Jezreel Valley 1930000, Israel; andreyk@yvc.ac.il; Tel.: +972-54-564-5735

Academic Editor: Pascal Stiefenhofer

Received: 24 August 2017; Accepted: 27 September 2017; Published: 1 October 2017

\begin{abstract}
The present study explores the effect of the gambler's fallacy on stock trading volumes. I hypothesize that if a stock's price rises (falls) during a number of consecutive trading days, then the gambler's fallacy may cause at least some of the investors to expect that the stock's price "has" to subsequently fall (rise), and thus, to increase their willingness to sell (buy) the stock, resulting in a stronger degree of disagreement between the investors and a higher-than-usual stock trading volume on the first day when the stock's price indeed falls (rises). Employing a large sample of daily price and trading volume data, I document that following relatively long sequences of the same-sign stock returns, on the days when the sign is reversed, the trading activity in the respective stocks is abnormally high. Moreover, average abnormal trading volumes gradually and significantly increase with the length of the preceding return sequence. The effect is slightly more pronounced following the sequences of negative stock returns, and remains significant after controlling for other potentially influential factors, including contemporaneous and lagged actual and absolute stock returns, historical stock returns and volatilities, and company-specific events, such as earnings announcements and dividend payments.
\end{abstract}

Keywords: gambler's fallacy; investment decisions; stock return sequences; trading volumes

JEL Classification: G02; G11; G12; G19

\section{Introduction}

The major goal of any market, including the stock exchange, is to facilitate the trading activity in it. Therefore, any kind of analysis dealing with financial markets has to seriously take stock trading volumes into account.

A vast strand of financial literature is concerned with better understanding of nature of stock trading activity. The previous studies identify several factors that may potentially give rise to the trading process, including portfolio rebalancing reasons (e.g., Hirshleifer et al. 1994, 2006; Hong and Stein 1999; Chordia et al. 2007), dispersion in investors' expectations and different interpretations of information events and potential risks (e.g., Karpoff 1986, 1987; Kandel and Pearson 1995; Llorente et al. 2002; Lo and Wang 2006), and presence of irrational traders (e.g., Baker and Stein 2004; Hong and Yu 2009).

Another major empirical fact that is clearly stated by the previous financial literature is that there exists an imprescriptible link between stock prices and trading volumes. The strand of literature dealing with this link provides a wide range of important findings, indicating that absolute values of daily stock returns and contemporaneous trading volumes are positively correlated for both market indices and individual stocks (e.g., Westerfield 1977; Rutledge 1984; Karpoff 1987; Schwert 1989; Gallant et al. 1992); there is also a positive relationship between absolute values of daily stock returns and contemporaneous changes in trading volume (e.g., Crouch 1970; Epps and Epps 1976; Harris 1983; Pathirawasam 2011); trading volumes tend to be higher when the stock prices are rising 
(e.g., Campbell et al. 1993; Saatccioglu and Starks 1998; Llorente et al. 2002); and positive stock returns lead to higher subsequent trading volumes (e.g., Statman et al. 2006; Griffin et al. 2007; Glaser and Weber 2009).

Stock trading volumes also tend to increase following company-specific events, such as earnings announcements (e.g., Varian 1989; Holthausen and Verrecchia 1990; Kandel and Pearson 1995; Bamber et al. 1997, 2011; Barron et al. 2005; Garfinkel and Sokobin 2006; Hong and Stein 2007; Israeli 2015) or dividend announcements and payments (e.g., Lakonishok and Vermaelen 1986; Bajaj and Vijh 1995; Xu et al. 2002; Tran and Mai 2015; Ndjadingwe and Radikoko 2015).

In the present study, I make an effort to shed light on an additional aspect of the relationship between the mutually dependent concepts of stock prices and trading volumes. I join the rapidly growing strand of literature that deals with various behavioral factors affecting the trading volumes (e.g., Barber and Odean 2008; Huddart et al. 2009; Kliger and Kudryavtsev 2010) and analyze the effect of the gambler's fallacy on the latter. The gambler's fallacy (Laplace [1796] 1951) is one of the oldest documented psychological biases and refers to an (incorrect) belief in negative autocorrelation of random sequences that are in fact non-autocorrelated. For example, a person whose expectations are based on the gambler's fallacy believes that after three red numbers appearing on the roulette wheel, a black number is "due," that is, becomes more likely to appear than a red one. In this respect, I suggest that if a stock's price rises (falls) during a number of consecutive trading days, then the gambler's fallacy may cause at least some of the intuitively acting investors to expect that the stock's price "has" to subsequently fall (rise), and thus, to increase their willingness to sell (buy) the stock, resulting in a stronger degree of disagreement between the investors and a higher than usual stock trading volume on the first day when the stock's price indeed falls (rises). In other words, I expect that relatively long sequences of the same-sign stock returns may enhance the trading activity in the respective stock on the days when the stock return's sign is reversed. In addition, I hypothesize that, just like in the case of a casino where people are more prone to bet on a black number the longer the consecutive series of red numbers appearing on the wheel, in the case of the security market, stock trading volume may be more strongly increased after the stock return's sign reversal the longer the preceding sequence of the days with the opposite sign of the stock's returns.

Employing the daily price and trading volume data for all the constituents of S \& P 500 Index during the years 1990 to 2016, I find supportive evidence for both research hypotheses of the study. First, I document that following the sequences of three, four, five, six and seven or more days of both positive and negative stock returns, on the days when the stock returns' sign is reversed, abnormal trading volumes are on average significantly positive, indicating an abnormally high stock trading activity. This effect appears to be slightly more pronounced following the sequences of negative, compared to the respective sequences of positive, stock returns, possibly indicating that the latter represent more salient events from investors' viewpoint, thus increasing their inclination to rely on simplifying decision-making techniques. Second, average abnormal trading volumes gradually and significantly increase with the return sequence length, being 2.5 to 3 times higher following the sequences of seven or more days, relatively to the sequences of three days. Furthermore, by running multifactor regressions, I document that the return sequence effect on stock trading volumes persists and remains significant after controlling for other potentially influential factors, including contemporaneous and lagged actual and absolute stock returns, historical stock returns and volatilities, and company-specific events, such as earnings announcements and dividend payments.

The rest of the paper is structured as follows. Section 2 reviews the literature dealing with stock trading volumes and the gambler's fallacy. In Section 3, I formulate and explain the study's research hypotheses. Section 4 describes the database employed in this study. Section 5 introduces the empirical tests and presents the results. Section 6 concludes and provides a brief discussion. 


\section{Literature Review}

\subsection{Stock Trading Volumes and Their Connection to Stock Returns}

The literature on financial markets has traditionally concentrated more heavily on trying to explain and predict asset prices, while trading activity has been paid significantly less attention. Yet trading activity as an important feature of financial markets is intensive and continuously increasing, and, thus, warrants separate examination.

Prior studies suggest and discuss a number of factors that may explain and drive the trading activity. Beaver (1968) is the first to note that volume is a useful tool in determining how much disagreement exists with the arrival of new information. He argues that anything that causes investors to act can be described as information, whether or not it truly has any fundamental impact on the underlying valuation of the company. Karpoff (1986) demonstrates that trading volume results from dispersion in prior expectations and idiosyncratic interpretations of information events. He also shows that the increase in trading volume is positively correlated with the information "surprise". According to Karpoff (1987), if a "surprise" is followed by stock price revision in the direction corresponding to the quality of the "surprise", then the contemporaneous trading volume increases with the absolute value of the price change. Kim and Verrecchia (1991) continue Karpoff's line of research and define a measure of market's information asymmetry as a ratio of volume to the absolute value of price change. In addition, they argue that volume may increase either with the absolute value of stock returns, reflecting the average change in investors' expectations, or following an increase in information asymmetry. Harris and Raviv (1993) and Kandel and Pearson (1995) suggest that investors employ the same public information, but interpret it differently, a scenario which results in trading activity.

Investors may also trade for portfolio rebalancing reasons, the fact that gives rise to liquidity (or noise) trading, which is not based on information. The volume of liquidity trading may be a function of past returns as predicted by a number of theoretical models (e.g., De Long et al. 1990; Hong and Stein 1999; Hirshleifer et al. 1994, 2006). Chordia et al. (2007) conclude that liquidity trading is based on stock visibility (proxied by firm size, age, price and the book-to-market ratio), portfolio rebalancing needs, differences of opinion (proxied by forecast dispersion and firm leverage), and uncertainty about fundamental values.

Llorente et al. (2002) propose a model, in which the trading process is driven by investor's expectations of the future stock price returns and exposure to the risk in equilibrium conditions. Lo and Wang (2006) describe an intertemporal equilibrium model of stock trading and pricing with multiple assets and heterogeneous investors. In Baker and Stein (2004), high trading volume indicates the presence of irrational traders who push up prices (their model also involves short sale constraints). In Hong and Yu (2009), high volume indicates the presence of noise traders.

Trading volume may also be connected to specific stock return patterns, such as momentum and reversal. In their pioneering work, Jegadeesh and Titman (1993) present a significant evidence for the existence of price momentum, by documenting that trading strategies which buy stocks that have performed well in the past and sell stocks that have performed poorly in the past generate significant positive returns over 3 - and 12-month holding periods. Nevertheless, these systematic short-term stock price patterns are still regarded as anomaly and represent a serious challenge for the researchers. Fama and French (1996) demonstrate that their famous three-factor model is able to explain most asset pricing phenomena, but not the short-term return momentum. $\mathrm{Wu}$ (2002) continues their line of research and shows that the incorporation of conditioning information into an asset-pricing model may be a proper way to capture return momentum. His results indicate that both SMB and HML risks are time-varying and that momentum and reversal return patterns have different time-varying risk characteristics. Lee and Swaminathan (2000) argue that past trading volume provides an important link between "momentum" and "value" strategies. Specifically, they find that firms with high (low) past turnover ratios exhibit many glamour (value) characteristics, earn lower (higher) future returns, and have consistently more negative (positive) earnings surprises over the next two years. Price 
momentum effects appear to reverse over the next five years, and high (low) volume winners (losers) experience faster reversals. This suggests that past trading volume may serve as a predictor for both the magnitude and the persistence of price momentum.

Stock trading volume is a concept that is closely related to the one of stock prices and returns. The early studies on volume-price relation argue that positive relations between the absolute value of daily price changes and daily volumes exist for both market indices and individual stocks (e.g., Ying 1966; Westerfield 1977; Rutledge 1984; Karpoff 1987; Schwert 1989; Gallant et al. 1992). Furthermore, Epps $(1975,1977)$ demonstrates that both in the stock and bond markets, the ratio of volume to absolute price change is larger for transactions when a security price rises than when it falls. Another group of studies point out at a positive relationship between absolute price changes and contemporaneous volume changes (e.g., Crouch 1970; Epps and Epps 1976; Harris 1983).

More recent studies pay more attention to different kinds of lag or inter-day relations between stock returns and trading volumes (e.g., Chen et al. 2001; Khan and Rizwan 2008; Lee and Rui 2002; Pisedtasalasai and Gunasekarage 2007), and introduce additional relevant factors into their analysis. Saatccioglu and Starks (1998) find that volume leads stock price changes in four out of the six emerging markets. Gervais et al. (2001) investigate the role of trading activity in terms of the information it contains about future prices, and find that individual stocks whose trading volume is usually large (small) over period of a day or a week, tend to experience large (small) returns over the subsequent month. Ziebart (1990) states that the trading volume is positively correlated with the absolute changes in the mean analyst forecasts. Campbell et al. (1993) and Llorente et al. (2002) report the dynamic relation between volume and returns in the cross-section. Safvenblad (2000) reveals that Swedish index returns exhibit high autocorrelation when trading volume is low. Griffin et al. (2007) investigate the dynamic relation between market-wide trading activity and returns in 46 markets and report a strong positive relationship between turnover and past returns. Statman et al. (2006) and Glaser and Weber (2009) document similar results.

Pathirawasam (2011) documents that stock returns are positively related to the contemporary changes in trading volumes. Moreover, he finds that past trading volume change is negatively related to stock returns, and argues that this negative relationship may be caused by investor misspecification about future earnings or illiquidity of low volume stocks. Caginalpa and Desantisa (2011) point out that if the stock price is growing, but the trading volume is declining, then stock price growth is considered by technical analysts as unstable. Remorov (2014) presents a model of stock price and volume behavior during market crashes and finds that trading volume is inversely proportional to the square of the stock price in the case of the sharp price declines, the result being empirically supported by price and volume data for major recent US stock bankruptcies and market crashes.

A vast strand of literature deals with the effects of company-specific events on stock trading volumes. Probably the most widely discussed fact in this respect is the systematic and significant increase in the trading volumes following earnings announcements. Previous research identifies three major sources of these abnormally high trading volumes, all stemming from some form of heterogeneity among investors: (i) differences in information (e.g., Varian 1989; Holthausen and Verrecchia 1990; Kim and Verrecchia 1991, 1994, 1997; Barron et al. 2005); (ii) differing risk preferences (e.g., Beaver 1968; Verrecchia 1981), and (iii) differences in opinion, that is, differential interpretation of the earnings news (e.g., Harris and Raviv 1993; Kandel and Pearson 1995; Bamber et al. 1997, 1999; Garfinkel and Sokobin 2006; Hong and Stein 2007; Bamber et al. 2011). Israeli (2015) demonstrates that trading volume reactions to earnings announcements provide information about future returns that cannot be deduced from the price reactions or the magnitudes of earnings surprises.

Another company-specific factor whose influence on stock trading volumes is well documented is made up of dividend announcements and payments. Lakonishok and Vermaelen (1986) report higher trading volumes before and after ex-dividend days, and observe higher volume increases for stocks with higher yields. Xu et al. (2002) conclude that public announcements on dividends tend to be accompanied by abnormal trading activity due to the pre-announcement disagreement and after-announcement 
agreement theory they develop. Bajaj and Vijh (1995) also support the information assimilation view by showing that there is a lot of information generated around the announcement period. Therefore, abnormal trading and excess returns are attributed to dividend information. Tran and Mai (2015) document that dividend announcements lead to positive effects on stock prices and trading volumes. Similarly, Ndjadingwe and Radikoko (2015) reveal that there is a direct relationship between dividend announcement, ex-dividends, dividend payout ratio and volume of stock traded and the stock price.

In recent years financial literature pays more attention to behavioral factors potentially affecting trading volumes. Barber and Odean (2008) suggest that investors are net buyers and professional investors are net sellers of stocks when attention to those stocks is likely to be high, as indirectly measured by their presence in the news, high trading volume, and extreme returns. Subsequently, Huddart et al. (2009) document that trading volumes are strikingly higher, in both economical and statistical terms, when the current stock price is higher (lower) than the previous fifty-two week high (low) price, the latter being widely-reported as a benchmark in the business press, and conclude that the increase in volume is driven by increased investor attention when a stock's price is outside of its usual trading range. Kliger and Kudryavtsev (2010) reveal that abnormal trading volumes following analyst recommendation upgrades (downgrades) are significantly higher if the latter are issued on the days when the general stock market index rises (falls). They explain this finding by the availability heuristic (Tversky and Kahneman 1973) ${ }^{1}$. In other words, the availability heuristic may be described as a rule of thumb people use to estimate the probability of an outcome based on how easy that outcome is to imagine., suggesting that stock market index returns of the same sign make the respective recommendation revisions look more salient, or more available from investors' point of view.

In the present study, I make an effort to contribute to this strand of literature by testing the effect of the gambler's fallacy on stock trading volumes.

\subsection{Gambler's Fallacy}

The gambler's fallacy is defined as an (incorrect) belief in negative autocorrelation of non-autocorrelated random sequences. For example, individuals whose expectations are based on the gambler's fallacy believe that after three red numbers appearing on the roulette wheel, a black number is "due," that is, becomes more likely to appear than a red number.

The first published account of this psychological bias is by Laplace [1796] (1951). Gambler's fallacy-type beliefs are first observed in the laboratory (under controlled conditions) in the literature on probability matching. In these experiments, subjects are asked to guess which of two colored lights would next illuminate. After seeing a string of one outcome, subjects are significantly more likely to guess the other, an effect referred to in that literature as negative recency (see Estes 1964; Lee 1971, for reviews). Ayton and Fischer (2004) demonstrate the existence of similar beliefs in the lab when subjects choose which of two colors will appear next on a simulated roulette wheel. Gal and Baron (1996) show that gambler's fallacy behavior is not simply caused by boredom. They ask participants in their experiments how they would best maximize their earnings, and get responses based on gambler's fallacy type logic.

The gambler's fallacy is thought to be caused by the representativeness heuristic (Tversky and Kahneman 1971; Kahneman and Tversky 1972). Here, chance is perceived as "a self-correcting process in which a deviation in one direction induces a deviation in the opposite direction to restore the equilibrium" (Tversky and Kahneman 1974, p. 1125). Thus, after a sequence of three red numbers appearing on the roulette wheel, black is more likely to occur than red because a sequence "red-red-red-black" is more representative of the underlying distribution than a sequence "red-red-red-red".

1 The availability heuristic refers to the phenomenon of determining the likelihood of an event according to the ease of recalling similar instances 
A number of researchers demonstrate the existence of the gambler's fallacy empirically, in lottery and horse or dog racing settings. For example, Clotfelter and Cook $(1991,1993)$ and Terrell (1994) demonstrate that soon after a lottery number wins, people are significantly less likely to place their bets on it. This effect diminishes over time; months later the winning number is as popular as the average number. Terrell and Farmer (1996) and Terrell (1998) show the effects of this fallacy in horse and dog racing. Croson and Sundali (2005) and Sundali and Croson (2006) use videotapes of play of a roulette table in casino and document a significant gambler's fallacy in betting. That is, following a sequence of one-color outcomes, people are more likely to bet on the other color.

Zielonka (2004) asks a group of stock market professionals a number of questions aimed at detecting their way of making decisions, and documents that market "signals" considered by technical analysts are consistent with a number of behavioral biases, including gambler's fallacy. Goetzmann and Kumar (2008) document that U.S. investors who exhibit trend-contrarian behavior (gambler's fallacy) hold less diversified portfolios, implying negative risk and performance consequences. Kudryavtsev et al. (2013) conduct a survey among stock market investors and quantify the extent to which each of them is affected by a number of behavioral biases, including the gambler's fallacy. They conclude that the degrees of the biases are positively correlated in the cross-section, that is, if an investor accepts certain intuitive decision-making technique, she will probably not reject other ones, as well.

Overall, the gambler's fallacy is well documented both in the laboratory and in the real world, including money-related behavior. Yet, on the other hand, there seems to be little evidence of this behavioral pattern in financial, including stock market decision-making.

\section{Research Hypotheses}

As discussed in the previous Section, there exists a close interdependence between stock prices and returns, on the one hand, and stock trading volumes, on the other hand. The present study analyzes another aspect of the relationship between these mutually dependent concepts.

I suggest that if a stock's price rises (falls) during a number of consecutive trading days, then the gambler's fallacy may cause at least some of the "psychology-oriented" investors to expect that the stock's price "has" to subsequently fall (rise), and thus, to increase their willingness to sell (buy) the stock, creating selling (buying) pressure. In both cases, the degree of disagreement between the investors may be increased, resulting in higher than usual stock trading volume on the first day when the stock's price indeed falls (rises). Moreover, I expect that, just like in the case of a casino where the feverish striving for betting on a black number grows with the length of the consecutive series of red numbers appearing on the wheel, the stock trading volume may be more strongly increased the longer the sequence of the days with the same sign of the stock's returns. Respectively, this study's two research hypotheses are formulated as follows:

Hypothesis 1. Stock trading volume should be higher on the days when the stock return's sign is reversed after a number of consecutive days with the same-sign returns.

Hypothesis 2. The increase in the stock trading volume following the reversal in the sign of the stock's return should be more pronounced the longer the sequence of the days with the same sign of the stock's returns.

In other words, I suggest that relatively long sequences of the same-sign stock returns may enhance the trading activity in the respective stock, and furthermore test for the existence of this "return sequence" effect.

\section{Data Description}

In my empirical analysis, I employ the adjusted daily price and trading volume data for all the constituents of S \& P 500 Index as of 31 December 2016, as recorded at www.finance.yahoo.com. The sampling period for each given stock starts on 1 January 1990 or at the first day of the stock's 
trading history reported by the website, and ends on 31 December 2016, yielding an overall sample of 2,425,650 stock-days. Daily values of the S \& P 500 Index, which I use as a proxy for the general stock market index, are downloaded from the same website.

For each trading day $t$, I calculate the daily returns of all the stocks and of the market index. Furthermore, for each stock $i$, I normalize the abnormal trading volume in the time series, that is, calculate:

$$
A B V O L_{i t}=\frac{V_{o l} l_{i t}-A V o l_{i}}{S T D V o l_{i}}
$$

where: $A B V O L_{i t}$ is stock $i$ 's abnormal trading volume on day $t, V_{i t}$ is stock $i$ 's trading volume on day $t, A V o l_{i}$ is stock $i$ 's average trading volume over 250 trading days preceding day $t$, and $S T D V o l_{i}$ is the standard deviation of stock $i$ 's average trading volume over 250 trading days preceding day $t^{2}$. Both $V_{o l} l_{i t}$ and $A V o l_{i}$ are adjusted for stock splits.

Finally, for all the stocks in our sample, I record the dates of the dividend payments, and of the quarterly earnings announcements, the latter being provided by Thomson First Call.

\section{Research Methodology and Results}

\subsection{Return Sequence Effect on Stock Trading Volumes: Comparative Analysis}

First of all, I perform a simple calculation of abnormal trading volumes following sequences of days characterized by the same-sign stock returns. In order to be able to simultaneously test the both research hypotheses, I define a number of alternative return sequence lengths, namely: (i) three days; (ii) four days; (iii) five days; (iv) six days; (v) seven days or more. Since the return sequence effect may be expected to emerge on the trading day when the return sign is reversed, I append the days with exactly zero stock returns to the sequences. That is, for example, if a stock's returns were positive during three consecutive days, zero on the fourth day, positive again on the fifth day and negative on the sixth day, I consider that as a sequence of five positive-return trading days and calculate the stock's abnormal trading volume on the sixth day when the return sign is first reversed.

Table 1 reports average abnormal trading volumes for the days following the sequences of different length of positive and negative stock returns. In addition, the table presents the differences in the average abnormal volumes between the sequences of different length, and their statistical significance.

The results corroborate both research hypotheses. First, in line with Hypothesis 1, following the sequences of all lengths of both positive and negative stock returns, on the days when the stock returns' sign is reversed, abnormal trading volumes are on average significantly positive, indicating an abnormally high stock trading activity. Second, consistently with Hypothesis 2, average abnormal trading volumes gradually and significantly increase with the sequence length. For example, average abnormal volumes following the sequences of positive (negative) stock returns equal 0.096 (0.106) for the sequence length of three days, compared to 0.249 (0.296) for the sequence length of seven or more days. An additional observation is that the average abnormal volumes are slightly higher following the sequences of negative, compared to positive, stock returns, possibly suggesting that the latter represent more salient (and probably more psychologically traumatic) events from investors' viewpoint, thus increasing their inclination to rely on simplifying decision-making techniques. ${ }^{3}$

2 Abnormal trading volumes for each stock are calculated starting from the first day preceded by 250 trading days within the working sample, the latter starting from 1 January 1990, or from the first day of the stock's reported trading history.

3 As a robustness check, I have repeated the analysis for return sequences of random signs. For each return sequence length, I have randomly drawn from my working sample 100,000 sequences of stock trading days without establishing any condition for the sign of stock returns, and have calculated average abnormal trading volumes on the days immediately following the sequences. For all the sequence lengths, average abnormal volumes were not significantly different from zero. These results (available in detail upon request from the author) suggest that the findings reported in Table 1 are driven by the same-sign return sequences. 
Table 1. Average abnormal trading volumes following sequences of the same-sign stock returns.

\begin{tabular}{|c|c|c|c|c|}
\hline \multicolumn{5}{|c|}{$\begin{array}{c}\text { Panel A: Average Abnormal Trading Volumes (t-Statistics) for the Days Following the } \\
\text { Sequences of Positive Stock Returns }\end{array}$} \\
\hline 3 Days & 4 Days & 5 Days & 6 Days & 7 Days or More \\
\hline ** 0.096 (1.98) & $* * 0.124(2.15)$ & $* * * 0.154(2.56)$ & *** $0.191(3.29)$ & $* * * 0.249(4.64)$ \\
\hline $\begin{array}{r}\text { Differences on } \\
\text { ABVO } \\
\text { ABVO } \\
\text { ABVO } \\
\text { ABVO } \\
\text { ABVO }\end{array}$ & $\begin{array}{l}\text { rage abnormal } \\
4 \text { days) - ABV( } \\
5 \text { days) - ABV } \\
6 \text { days) - ABV } \\
+ \text { days) - ABV } \\
+ \text { days) - ABV }\end{array}$ & $\begin{array}{l}\text { ames }(\mathrm{t}-\mathrm{statistics} \\
(3 \text { days }) \\
(4 \text { days }) \\
(5 \text { days }) \\
(6 \text { days }) \\
(3 \text { days })\end{array}$ & $\begin{array}{l}* 0.02 \\
* 0.03 \\
* * 0.0 \\
* * 0.0 \\
* * * 0.1\end{array}$ & $\begin{array}{l}(1.71) \\
(1.79) \\
(1.96) \\
(2.28) \\
(2.98)\end{array}$ \\
\hline \multicolumn{5}{|c|}{$\begin{array}{c}\text { Panel B: Average Abnormal Trading Volumes (t-Statistics) for the Days Following the } \\
\text { Sequences of Negative Stock Returns }\end{array}$} \\
\hline 3 Days & 4 Days & 5 Days & 6 Days & 7 Days or More \\
\hline ** 0.106 (2.06) & $* * * 0.149(2.42)$ & $* * * 0.185(2.97)$ & $* * * 0.240(3.88)$ & $* * * 0.296(5.71)$ \\
\hline $\begin{array}{r}\text { Differences on } \\
\text { ABVO } \\
\text { ABVO } \\
\text { ABVO } \\
\text { ABVO } \\
\text { ABVO }\end{array}$ & $\begin{array}{l}\text { rage abnormal } \\
4 \text { days) - ABV } \\
5 \text { days) - ABV } \\
6 \text { days) - ABVC } \\
\text { + days) - ABV } \\
+ \text { days) - ABV }\end{array}$ & $\begin{array}{l}\text { umes }(\mathrm{t} \text {-statistics } \\
(3 \text { days }) \\
(4 \text { days }) \\
(5 \text { days }) \\
(6 \text { days }) \\
(3 \text { days })\end{array}$ & $\begin{array}{l}* 0.03 \\
* * 0.0 \\
* * 0.05 \\
* * 0.0 \\
* * * 0.1\end{array}$ & $\begin{array}{l}(1.86) \\
(1.99) \\
(2.21)) \\
(2.31) \\
(3.45)\end{array}$ \\
\hline
\end{tabular}

Asterisks denote 2-tailed $p$-values: ${ }^{*} p<0.10 ;{ }^{* *} p<0.05 ;{ }^{* * *} p<0.01$.

\subsection{Return Sequence Effect on Stock Trading Volumes: Multifactor Regression Analysis}

After documenting that stock trading volumes tend to be higher on the days when the respective stocks' returns reverse their sign after a sequence of days characterized by opposite-sign returns, the next stage is to check if this result holds when other potentially influential factors are controlled for.

Stock returns, both actual and absolute, obviously represent a factor that is most strongly correlated with stock trading volumes (e.g., Karpoff 1987; Chen et al. 2001; Llorente et al. 2002; Griffin et al. 2007). Therefore, actual and absolute stock returns are also the first factor to be controlled for in order to verify that the results reported in the previous Subsection are not driven by the well-documented correlation between stock trading volumes and returns. In order to do that, I run the following two (alternative) regressions based on the panel data of stock trading volumes and returns over the sampling period:

$$
\begin{aligned}
& A B V O L_{i t}=\alpha_{i}+\beta_{1 i} P O S 3_{i t}+\beta_{2 i} P O S 4_{i t}+\beta_{3 i} P O S 5_{i t}+\beta_{4 i} P O S 6_{i t}+ \\
& +\beta_{5 i} P \text { OS7plus }_{i t}+\beta_{6 i} N E G 3_{i t}+\beta_{7 i} N E G 4_{i t}+\beta_{8 i} N E G 5_{i t}+\beta_{9 i} N E G 6_{i t}+ \\
& +\beta_{10 i} N E G 7 \text { plus } i t+\beta_{11 i} S R_{i t}+\varepsilon_{i t} \\
& A B V O L_{i t}=\alpha_{i}+\beta_{1 i} P O S 3_{i t}+\beta_{2 i} P O S 4_{i t}+\beta_{3 i} P O S 5_{i t}+\beta_{4 i} P O S 6_{i t}+ \\
& +\beta_{5 i} P^{P O S 7 p l u s} \text { sit }+\beta_{6 i} N E G 3_{i t}+\beta_{7 i} N E G 4_{i t}+\beta_{8 i} N E G 5_{i t}+\beta_{9 i} N E G 6_{i t}+ \\
& +\beta_{10 i} N E G 7 \text { plus }_{i t}+\beta_{11 i}\left|S R_{i t}\right|+\varepsilon_{i t}
\end{aligned}
$$

where: $P O S 3_{i t}$ to $P O S 7 p l u s_{i t}$ are the dummy variables, taking the value 1 if on the day $t$, stock $i$ 's return is negative following three to seven or more days of positive returns, respectively, and 0 otherwise; $N E G 3_{i t}$ to $N E G 7$ plus $_{i t}$ are the dummy variables, taking the value 1 if on the day $t$, stock $i$ 's return is positive following three to seven or more days of negative returns, respectively, and 0 otherwise; $S R_{i t}$ is stock $i^{\prime} \mathrm{s} \log$ return on day $t$; and $\left|S R_{i t}\right|$ is the absolute value of stock $i^{\prime} \mathrm{s} \log$ return on day $t$.

Tables 2 and 3 comprise the results of regressions (2) and (3), respectively, including the coefficient estimates, the differences between them, and their statistical significance. The results indicate that: 
- The coefficient estimates of all the dummy variables related to the preceding return sequences are positive and statistically significant. This represents a strong support for Hypothesis 1, demonstrating that the sign reversal of a stock's return following a sequence of opposite-sign return days increases the stock's daily trading volume beyond the well-documented positive correlation of the latter with the actual and absolute stock returns.

- For both positive and negative return sequences, the sequence dummies' coefficient estimates significantly increase with the sequence length, supporting Hypothesis 2.

- Consistently with the previous Subsection's findings, the coefficient estimates of NEG dummies are slightly higher than those of the respective POS ones, indicating that the return sequence effect on stock trading volumes is slightly more pronounced following negative return sequences.

- In line with the previous literature, the coefficient estimates of $S R_{t}$ and $\left|S R_{i}\right|$ are positive, the latter being both higher and more statistically significant. This suggests that stock trading volumes are positively correlated with the actual, and even more with the absolute stock returns.

Table 2. Regression analysis (regression (2)): Return sequence effect on stock trading volumes (Dependent variable-ABVOL).

\begin{tabular}{cccc}
\hline $\begin{array}{c}\text { Explanatory Variables } \\
\text { (Coefficients) }\end{array}$ & $\begin{array}{c}\text { Coefficient Estimates } \\
\text { (t-Statistics) }\end{array}$ & Coefficient Differences & $\begin{array}{c}\text { Value of Coefficient } \\
\text { Differences (t-Statistics) }\end{array}$ \\
\hline Intercept $(\alpha)$ & $* * *-0.165(-16.38)$ & Positive sequences: & \\
POS3t $(\beta 1)$ & $* * 0.137(2.11)$ & $\beta 2-\beta 1$ & $* 0.025(1.72)$ \\
POS4t $(\beta 2)$ & $* * 0.162(2.28)$ & $\beta 3-\beta 2$ & $* * 0.036(2.01)$ \\
POS5t $(\beta 3)$ & $* * * 0.198(2.74)$ & $\beta 4-\beta 3$ & $* * 0.041(2.44)$ \\
POS6t $(\beta 4)$ & $* * * 0.239(3.67)$ & $\beta 5-\beta 4$ & $* * * 0.047(2.68)$ \\
POS7plust $(\beta 5)$ & $* * * 0.286(4.38)$ & Negative sequences: & $* .149(4.61)$ \\
NEG3t $(\beta 6)$ & $* * 0.148(2.34)$ & $\beta 7-\beta 6$ & $* * 0.036(2.10)$ \\
NEG4t $(\beta 7)$ & $* * * 0.184(2.85)$ & $\beta 8-\beta 7$ & $* * 0.047(2.39)$ \\
NEG5t $(\beta 8)$ & $* * * 0.231(3.12)$ & $\beta 9-\beta 8$ & $* * * 0.054(2.94)$ \\
NEG6t $(\beta 9)$ & $* * * 0.285(3.99)$ & $\beta 10-\beta 9$ & $* * 0.067(3.08)$ \\
NEG7plust $(\beta 10)$ & $* * * 0.352(4.87)$ & $\beta 10-\beta 6$ & $* * 204(6.14)$ \\
SRt $(\beta 11)$ & $* * 1.325(2.05)$ & 0.213 & \\
\hline Adjusted R-Squared & Asterisks denote 2-tailed $p$-values: ${ }^{*} p<0.10 ; * * p<0.05 ; * * *<0.01$. &
\end{tabular}

Table 3. Regression analysis (regression (3)): Return sequence effect on stock trading volumes (Dependent variable-ABVOL).

\begin{tabular}{cccc}
\hline $\begin{array}{c}\text { Explanatory Variables } \\
\text { (Coefficients) }\end{array}$ & $\begin{array}{c}\text { Coefficient Estimates } \\
\text { (t-Statistics) }\end{array}$ & Coefficient Differences & $\begin{array}{c}\text { Value of Coefficient } \\
\text { Differences (t-Statistics) }\end{array}$ \\
\hline Intercept $(\alpha)$ & $* * *-0.186(-19.65)$ & Positive sequences: & $* 0.026(1.74)$ \\
POS3t $(\beta 1)$ & $* * 0.140(2.18)$ & $\beta 2-\beta 1$ & $* * 0.036(2.00)$ \\
POS4t $(\beta 2)$ & $* * 0.166(2.36)$ & $\beta 3-\beta 2$ & $* * 0.044(2.50)$ \\
POS5t $(\beta 3)$ & $* * * 0.207(2.89)$ & $\beta 4-\beta 3$ & $* * 0.048(2.71)$ \\
POS6t $(\beta 4)$ & $* * * 0.251(3.91)$ & $\beta 5-\beta 4$ & $* * 159(4.82)$ \\
POS7plust $(\beta 5)$ & $* * * 0.299(4.77)$ & $\beta 5-\beta 1$ & $* 0.036(2.08)$ \\
NEG3t $(\beta 6)$ & $* * 0.154(2.39)$ & Negative sequences: & $* 0.051(2.47)$ \\
NEG4t $(\beta 7)$ & $* * * 0.190(2.96)$ & $\beta 7-\beta 6$ & $* * 0.053(2.87)$ \\
NEG5t $(\beta 8)$ & $* * * 0.241(3.32)$ & $\beta 9-\beta 7$ & $* * 0.076(3.42)$ \\
NEG6t $(\beta 9)$ & $* * * 0.294(4.11)$ & $\beta 10-\beta 9$ & $* * * 0.214(6.28)$ \\
NEG7plust $(\beta 10)$ & $* * * 0.368(5.01)$ & $\beta 10-\beta 6$ & \\
ISRt I $(\beta 11)$ & $* * * 1.582(2.86)$ & &
\end{tabular}


Furthermore, I test if the return sequence effect on stock trading volumes persists after controlling for other potentially influential factors, in addition to contemporaneous stock returns. Namely, I consider lagged stock returns (e.g., following the findings by Chen et al. 2001; Khan and Rizwan 2008; Lee and Rui 2002; Pisedtasalasai and Gunasekarage 2007); historical performance of the stock prices, including both returns and their volatility (e.g., following the findings by Griffin et al. 2007; Caginalpa and Desantisa 2011; Remorov 2014); companies' earnings announcements (e.g., following the findings by Holthausen and Verrecchia 1990; Barron et al. 2005; Garfinkel and Sokobin 2006; Bamber et al. 2011; Israeli 2015); and dividend payments (e.g., following the findings by Lakonishok and Vermaelen 1986; Tran and Mai 2015; Ndjadingwe and Radikoko 2015).

Once again, I run two panel data regressions alternatively based on actual and absolute values of stock returns. The regressions are specified as follows:

$$
\begin{aligned}
& A B V O L_{i t}=\alpha_{i}+\beta_{1 i} P{ } O S 3_{i t}+\beta_{2 i} P O S 4_{i t}+\beta_{3 i} P O S 5_{i t}+\beta_{4 i} P O S 6_{i t}+ \\
& +\beta_{5 i} P \text { OS7plus } i t+\beta_{6 i} N E G 3_{i t}+\beta_{7 i} N E G 4_{i t}+\beta_{8 i} N E G 5_{i t}+\beta_{9 i} N E G 6_{i t}+
\end{aligned}
$$

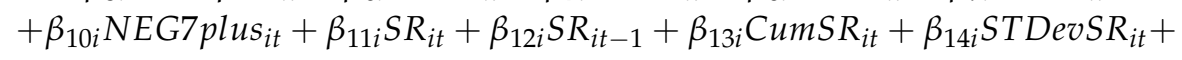

$$
\begin{aligned}
& +\beta_{15 i} \text { EarnAnn }_{i t}+\beta_{16 i} \text { Div }_{i t}+\varepsilon_{i t} \\
& A B V O L_{i t}=\alpha_{i}+\beta_{1 i} P O S 3_{i t}+\beta_{2 i} P O S 4_{i t}+\beta_{3 i} P O S 5_{i t}+\beta_{4 i} P O S 6_{i t}+ \\
& +\beta_{5 i} P_{\text {POS7plus }}+\beta_{6 i} N E G 3_{i t}+\beta_{7 i} N E G 4_{i t}+\beta_{8 i} N E G 5_{i t}+\beta_{9 i} N E G 6_{i t}+ \\
& +\beta_{10 i} N E G 7 \text { plus }_{i t}+\beta_{11 i}\left|S_{i t}\right|+\beta_{12 i}\left|S R_{i t-1}\right|+\beta_{13 i} \text { CumSR }_{i t}+\beta_{14 i} \text { STDevSR }_{i t}+ \\
& +\beta_{15 i} \text { EarnAnn }_{i t}+\beta_{16 i} \text { Div }_{i t}+\varepsilon_{i t}
\end{aligned}
$$

where: CumSR $_{i t}$ is stock $i$ 's cumulative return over 250 trading days (approximately one year) preceding day $t$; $S T D e v S R_{i t}$ is the standard deviation of stock $i$ 's returns over 250 trading days preceding day $t$; Earn $A n n_{i t}$ is the dummy variable, taking the value 1 if on day $t$ there was an earnings announcement published by firm $i$, and 0 otherwise; and $D i v_{i t}$ is the dummy variable, taking the value 1 if day $t$ represents an ex-dividend day for firm $i$, and 0 otherwise.

Tables 4 and 5 depict the results of regressions (4) and (5), respectively, suggesting that:

- The coefficient estimates of all POS and NEG dummy variables remain positive and significant, indicating that the return sequence effect on stock trading volumes is not driven by other relevant contemporaneous company-specific factors.

- Similarly to regressions (1) and (2), the sequence dummies' coefficient estimates significantly increase with the sequence length, suggesting that longer sequences of trading days with the same sign of stock returns enhance investors' tendency to expect reversal of direction of the stock price change.

- The coefficient estimates of NEG dummies remain slightly higher than those of the respective POS ones.

- The coefficient estimates of $S R_{t}, S R_{t-1},\left|S R_{i}\right|$ and $\left|S R_{i-1}\right|$ are positive and significant, demonstrating that both contemporaneous and lagged stock returns are positively correlated with stock trading volumes. Again, it should be noted that the effects of the absolute stock returns are slightly stronger pronounced than those of the actual stock returns.

- Daily stock trading volumes are positively and significantly correlated with the stocks' historical returns and return volatilities, and consistently with the previous literature, tend to be higher on the days of earnings announcements and on ex-dividend days. 
Table 4. Multifactor regression analysis (regression (4)): Return sequence effect on stock trading volumes (Dependent variable-ABVOL).

\begin{tabular}{|c|c|c|c|}
\hline $\begin{array}{l}\text { Explanatory Variables } \\
\text { (Coefficients) }\end{array}$ & $\begin{array}{l}\text { Coefficient Estimates } \\
\text { (t-Statistics) }\end{array}$ & Coefficient Differences & $\begin{array}{c}\text { Value of Coefficient } \\
\text { Differences (t-Statistics) }\end{array}$ \\
\hline Intercept $(\alpha)$ & $* * *-0.316(-24.10)$ & Positive sequences: & \\
\hline $\operatorname{POS} 3 t(\beta 1)$ & ** $0.121(2.00)$ & $\beta 2-\beta 1$ & * $0.026(1.74)$ \\
\hline POS4t ( $\beta 2)$ & ** $0.147(2.14)$ & $\beta 3-\beta 2$ & $* * 0.036(2.03)$ \\
\hline POS5t ( $\beta 3)$ & $* * * 0.183(2.62)$ & $\beta 4-\beta 3$ & $* * 0.038(2.28)$ \\
\hline POS6t ( $\beta 4)$ & $* * * 0.221(3.15)$ & $\beta 5-\beta 4$ & $* * * 0.043(2.50)$ \\
\hline POS7plust ( $\beta 5)$ & $* * * 0.264(3.97)$ & $\beta 5-\beta 1$ & $* * * 0.143(4.47)$ \\
\hline NEG3t $(\beta 6)$ & $* * 0.134(2.21)$ & Negative sequences: & \\
\hline$N E G 4 t(\beta 7)$ & $* * * 0.169(2.70)$ & $\beta 7-\beta 6$ & $* * 0.035(2.07)$ \\
\hline$N E G 5 t(\beta 8)$ & $* * * 0.214(2.99)$ & $\beta 8-\beta 7$ & $* * 0.045(2.31)$ \\
\hline$N E G 6 t(\beta 9)$ & $* * * 0.270(3.64)$ & $\beta 9-\beta 8$ & $* * * 0.056(2.98)$ \\
\hline NEG7plust $(\beta 10)$ & $* * * 0.336(4.58)$ & $\beta 10-\beta 9$ & $* * * 0.066(3.02)$ \\
\hline SRt $(\beta 11)$ & ${ }^{*} 1.147(1.84)$ & $\beta 10-\beta 6$ & $* * * 0.202(6.05)$ \\
\hline$S R t-1(\beta 12)$ & * $0.784(1.67)$ & & \\
\hline CumSRt ( $\beta 13)$ & * $0.127(1.78)$ & & \\
\hline STDevSRt ( $\beta 14)$ & $* * 0.097(2.03)$ & & \\
\hline EarnAnnt ( $\beta 15)$ & $* * * 0.112(4.34)$ & & \\
\hline $\operatorname{Divt}(\beta 16)$ & $* * * 0.075(3.85)$ & & \\
\hline Adjusted R-Squared & 0.487 & & \\
\hline
\end{tabular}

Table 5. Multifactor regression analysis (regression (5)): Return sequence effect on stock trading volumes (Dependent variable-ABVOL).

\begin{tabular}{|c|c|c|c|}
\hline $\begin{array}{l}\text { Explanatory Variables } \\
\text { (Coefficients) }\end{array}$ & $\begin{array}{c}\text { Coefficient Estimates } \\
\text { (t-Statistics) }\end{array}$ & Coefficient Differences & $\begin{array}{c}\text { Value of Coefficient } \\
\text { Differences (t-Statistics) }\end{array}$ \\
\hline Intercept $(\alpha)$ & $* * *-0.335(-25.17)$ & & \\
\hline POS3t $(\beta 1)$ & $* * 0.128(2.11)$ & & \\
\hline POS4t ( $\beta 2)$ & ** $0.155(2.23)$ & & \\
\hline POS5t ( $\beta 3)$ & $* * * 0.192(2.80)$ & Positive sequences: & \\
\hline POS6t ( $\beta 4)$ & $* * * 0.232(3.27)$ & $\beta 2-\beta 1$ & *0.027 (1.77) \\
\hline POS7plust ( $\beta 5)$ & $* * * 0.279(4.13)$ & $\beta 3-\beta 2$ & $* * 0.037(2.06)$ \\
\hline NEG3t $(\beta 6)$ & ** $0.141(2.32)$ & $\beta 4-\beta 3$ & $* * 0.040(2.37)$ \\
\hline$N E G 4 t(\beta 7)$ & $* * * 0.177(2.83)$ & $\beta 5-\beta 4$ & $* * * 0.047(2.61)$ \\
\hline$N E G 5 t(\beta 8)$ & $* * * 0.223(3.14)$ & $\beta 5-\beta 1$ & $* * * 0.151(4.62)$ \\
\hline$N E G 6 t(\beta 9)$ & $* * * 0.282(3.79)$ & Negative sequences: & \\
\hline NEG7plust ( $\beta 10)$ & $* * * 0.350(4.76)$ & $\beta 7-\beta 6$ & $* * 0.036(2.09)$ \\
\hline$|S R t|(\beta 11)$ & * $1.151(1.87)$ & $\beta 8-\beta 7$ & ** $0.046(2.35)$ \\
\hline$|S R t-1|(\beta 12)$ & * $0.782(1.66)$ & $\beta 9-\beta 8$ & $* * * 0.059(3.06)$ \\
\hline CumSRt ( $\beta 13)$ & * $0.129(1.81)$ & $\beta 10-\beta 9$ & $* * * 0.068(3.15)$ \\
\hline STDevSRt $(\beta 14)$ & $* * 0.101(2.10)$ & $\beta 10-\beta 6$ & $* * * 0.209(6.16)$ \\
\hline EarnAnnt ( $\beta 15)$ & $* * * 0.115(4.41)$ & & \\
\hline $\operatorname{Divt}(\beta 16)$ & $* * * 0.077(3.91)$ & & \\
\hline Adjusted R-Squared & 0.513 & & \\
\hline
\end{tabular}

\section{Conclusions and Discussion}

In the present study, I make an effort to contribute to the rapidly developing strand of literature that deals with behavioral factors affecting stock trading volumes. Namely, I hypothesize that investors' decisions to buy or sell stocks may be affected by the gambler's fallacy, and if so, stock daily trading volume may be higher when the sign of a stock's return is reversed following a relatively long sequence 
of days characterized by the opposite-sign stock's returns, and to increase even more with the length of the preceding return sequence.

Employing a large sample of daily price and trading volume data, I find corroborative evidence for the study's research hypotheses. First, I document that following both positive and negative stock return sequences of different length, on the days when the stock returns' sign is reversed, trading volumes tend to be significantly higher than usual. Second, the magnitude of the return sequence effect on stock trading volumes gradually and significantly increases with the return sequence length. Moreover, the multifactor regression analysis, explicitly accounting for the contemporaneous and lagged stock returns, demonstrates that this is not driven by a pure correlation between the latter and the stock returns, but rather by casino-like investors' expectations of stock price reversals. Finally, the effect also remains significant after controlling for historical stock returns and volatilities, and company-specific events, like earnings announcements and dividend payments.

The study's empirical findings may have a number of important practical implications. First, they imply that the multilevel and complicated mechanism of investors' trading activity may be affected by the gambler's fallacy, calling for further research that would test if this effect persists for shorter (intraday) and longer (weekly, monthly) time intervals, different sectors and categories of stocks, different countries, and different macroeconomic backgrounds, including the periods of financial crises. Second, if investors appear to intensify their trading activity following this kind of (not quite rational) considerations, it means that that in addition to the documented effect of the return sequences on the trading volumes, there may also be an effect on the stock prices themselves, which is not justified by other relevant factors. This may result in stocks' mispricing in the short run and create premises for the subsequent stock price "corrections". Therefore, in this respect, it might be interesting to analyze both the stock returns and the trading volumes over some short, including intraday, time intervals following the days when the stock return sign is reversed.

Conflicts of Interest: The author declares no conflict of interest.

\section{References}

Ayton, Peter, and Ilan Fischer. 2004. The Hot Hand Fallacy and the Gambler's Fallacy: Two Faces of Subjective Randomness? Memory and Cognition 32: 1369-78. [CrossRef] [PubMed]

Bajaj, Mukesh, and Anand M. Vijh. 1995. Trading Behavior and the Unbiasedness of the Market Reaction to Dividend Announcement. Journal of Finance 50: 255-79. [CrossRef]

Baker, Malcolm, and Jeremy Stein. 2004. Market Liquidity as a Sentiment Indicator. Journal of Financial Markets 7: 271-99. [CrossRef]

Bamber, Linda Smith, Orie E. Barron, and Thomas L. Stober. 1997. Trading Volume and Different Aspects of Disagreement Coincident with Earnings Announcements. The Accounting Review 72: 575-97.

Bamber, Linda Smith, Orie E. Barron, and Thomas L. Stober. 1999. Differential Interpretations and Trading Volume. The Journal of Financial and Quantitative Analysis 34: 369-86. [CrossRef]

Bamber, Linda Smith, Orie E. Barron, and Douglas E. Stevens. 2011. Trading Volume around Earnings Announcements and Other Financial Reports: Theory, Research Design, Empirical Evidence, and Directions for Future Research. Contemporary Accounting Research 28: 431-71. [CrossRef]

Barber, Brad M., and Terrance Odean. 2008. All That Glitters: The Effect of Attention and News on the Buying Behavior of Individual and Institutional Investors. Review of Financial Studies 21: 785-818. [CrossRef]

Barron, Orie E., David G. Harris, and Mary Stanford. 2005. Evidence That Investors Trade on Private Event-Period Information around Earnings Announcements. The Accounting Review 80: 403-21. [CrossRef]

Beaver, William H. 1968. The Information Content of Annual Earnings Announcements. Empirical Research in Accounting: Selected Studies, Supplement to Journal of Accounting Research 6: 67-92. [CrossRef]

Caginalpa, Gunduz, and Mark Desantisa. 2011. Stock Price Dynamics: Nonlinear Trend, Volume, Volatility, Resistance and Money Supply. Quantitative Finance 11: 849-61. [CrossRef]

Campbell, John Y., Sanford J. Grossman, and Jiang Wang. 1993. Trading Volume and Serial Correlation in Stock Returns. The Quarterly Journal of Economics 108: 905-39. [CrossRef] 
Chen, Gong-Meng, Michael Firth, and Oliver M. Rui. 2001. The Dynamic Relation between Stock Returns, Trading Volume and Volatility. The Financial Review 36: 153-74. [CrossRef]

Chordia, Tarun, Sahn-Wook Huh, and Avanidhar Subrahmanyam. 2007. The Cross-Section of Expected Trading Activity. Review of Financial Studies 30: 709-40. [CrossRef]

Clotfelter, Charles, and Philip J. Cook. 1991. Lotteries in the Real World. Journal of Risk and Uncertainty 4: 227-32. [CrossRef]

Clotfelter, Charles, and Philip J. Cook. 1993. The 'Gambler's Fallacy' in Lottery Play. Management Science 39: 1521-25. [CrossRef]

Croson, Rachel, and James Sundali. 2005. The Gambler's Fallacy and the Hot Hand: Empirical Data from Casinos. Journal of Risk and Uncertainty 30: 195-209. [CrossRef]

Crouch, R. L. 1970. A Nonlinear Test of the Random-Walk Hypothesis. American Economic Review 60: 199-202.

De Long, Bradford, Andrei Shleifer, Lawrence H. Summers, and Robert J. Waldmann. 1990. Positive Feedback Investment Strategies and Destabilizing Rational Speculation. Journal of Finance 45: 379-86. [CrossRef]

Epps, Thomas W. 1975. Security Price Changes and Transaction Volumes: Theory and Evidence. American Economic Review 65: 586-97.

Epps, Thomas W. 1977. Security Price Changes and Transaction Volumes: Some Additional Evidence. Journal of Financial and Quantitative Analysis 12: 141-46. [CrossRef]

Epps, Thomas W., and Mary Lee Epps. 1976. The Stochastic Dependence of Security Price Changes and Transaction Volumes: Implications for the Mixture-of-Distributions Hypothesis. Econometrica 44: 305-21. [CrossRef]

Estes, William. 1964. Probability Learning. In Categories of Human Learning. Edited by Arthur W. Melton. New York: Academic Press.

Fama, Eugene, and Kenneth French. 1996. Multifactor Explanations of Asset Pricing Anomalies. Journal of Finance 51: 55-84. [CrossRef]

Gal, Iddo, and Jonathan Baron. 1996. Understanding Repeated Simple Choices. Thinking and Reasoning 2: 81-98. [CrossRef]

Gallant, Ronald, Peter E. Rossi, and George Tauchen. 1992. Stock Prices and Volume. Review of Financial Studies 5: 199-242. [CrossRef]

Garfinkel, John A., and Jonathan Sokobin. 2006. Volume, Opinion Divergence, and Returns: A Study of Post-Earnings Announcement Drift. Journal of Accounting Research 44: 85-112. [CrossRef]

Gervais, Simon, Ron Kaniel, and Dan H. Mingelgrin. 2001. The High Volume Return Premium. Journal of Finance 56: 877-919. [CrossRef]

Glaser, Markus, and Martin Weber. 2009. Which Past Returns Affect Trading Volume? Journal of Financial Markets 12: 1-31. [CrossRef]

Goetzmann, William N., and Alok Kumar. 2008. Equity Portfolio Diversification. Review of Finance 12: 433-63. [CrossRef]

Griffin, John M., Federico Nardari, and René M. Stulz. 2007. Do Investors Trade More When Stocks Have Performed Well? Evidence from 46 Countries. Review of Financial Studies 20: 905-51. [CrossRef]

Harris, Larry. 1983. The Joint Distribution of Speculative Prices and of Daily Trading Volume. Working paper, University of Southern CA, Los Angeles, CA, USA.

Harris, Milton, and Artur Raviv. 1993. Differences of Opinion Make a Horse Race. Review of Financial Studies 6: 473-506. [CrossRef]

Hirshleifer, David, Avanidhar Subrahmanyam, and Sheridan Titman. 1994. Security Analysis and Trading Patterns When Some Investors Receive Information before Others. Journal of Finance 49: 1665-98. [CrossRef]

Hirshleifer, David, Avanidhar Subrahmanyam, and Sheridan Titman. 2006. Feedback and the Success of Irrational Investors. Journal of Financial Economics 81: 311-38. [CrossRef]

Holthausen, Robert W., and Robert E. Verrecchia. 1990. The Effect of Informedness and Consensus on Price and Volume Behavior. The Accounting Review 65: 191-208.

Hong, Harrison, and Jeremy C. Stein. 1999. A Unified Theory of Underreaction, Momentum Trading, and Overreaction in Asset Markets. Journal of Finance 54: 2143-84. [CrossRef]

Hong, Harrison, and Jeremy C. Stein. 2007. Disagreement and the Stock Market. Journal of Economic Perspectives 21: 109-28. [CrossRef]

Hong, Harrison, and Jialin Yu. 2009. Gone Fishin': Seasonality in Trading Activity and Asset Prices. Journal of Financial Markets 12: 672-702. [CrossRef] 
Huddart, Steven, Mark Lang, and Michelle H. Yetman. 2009. Volume and Price Patterns around a Stock's 52-Week Highs and Lows: Theory and Evidence. Management Science 55: 16-31. [CrossRef]

Israeli, Doron. 2015. Trading Volume Reactions to Earnings Announcements and Future Stock Returns. Working paper, Interdisciplinary Center Herzliya, Herzliya, Israel.

Jegadeesh, Narasimhan, and Sheridan Titman. 1993. Returns to Buying Winners and Selling Losers: Implications for Stock Market Efficiency. Journal of Finance 48: 65-91. [CrossRef]

Kahneman, Daniel, and Amos Tversky. 1972. Subjective Probability: A Judgment of Representativeness. Cognitive Psychology 3: 430-54. [CrossRef]

Kandel, Eugene, and Neil D. Pearson. 1995. Differential Interpretation of Public Signals and Trade in Speculative Markets. Journal of Political Economy 103: 831-72. [CrossRef]

Karpoff, Jonathan M. 1986. A Theory of Trading Volume. Journal of Finance 41: 1069-87. [CrossRef]

Karpoff, Jonathan M. 1987. The Relation between Price Changes and Trading Volume: A Survey. Journal of Financial and Quantitative Analysis 22: 109-26. [CrossRef]

Khan, Safi U., and Faisal Rizwan. 2008. Trading Volume and Stock Returns: Evidence from Pakistan's Stock Market. International Review of Business Research Papers 4: 151-62.

Kim, Oliver, and Robert E. Verrecchia. 1991. Market Reaction to Anticipated Announcements. Journal of Financial Economics 30: 273-309. [CrossRef]

Kim, Oliver, and Robert E. Verrecchia. 1994. Market Liquidity and Volume around Earnings Announcements. Journal of Accounting and Economics 17: 41-67. [CrossRef]

Kim, Oliver, and Robert E. Verrecchia. 1997. Pre-Announcement and Event-Period Private Information. Journal of Accounting and Economics 24: 395-419. [CrossRef]

Kliger, Doron, and Andrey Kudryavtsev. 2010. The Availability Heuristic and Investors' Reaction to Company-Specific Events. Journal of Behavioral Finance 11: 50-65. [CrossRef]

Kudryavtsev, Andrey, Gil Cohen, and Shlomit Hon-Snir. 2013. "Rational" or "Intuitive": Are Behavioral Biases Correlated across Stock Market Investors? Contemporary Economics 7: 31-53. [CrossRef]

Lakonishok, Josef, and Theo Vermaelen. 1986. Tax-Induced Trading around Ex-Dividend Days. Journal of Financial Economics 16: 287-319. [CrossRef]

Laplace, Pierre-Simon. 1951. A Philosophical Essay on Probabilities. New York: Dover. First published 1796.

Lee, Wayne. 1971. Decision Theory and Human Behavior. New York: Wiley.

Lee, Bong-Soo, and Oliver Rui. 2002. The Dynamic Relationship between Stock Return and Trading Volume: Domestic and Cross-Country Evidence. Journal of Banking and Finance 26: 51-78. [CrossRef]

Lee, Charles, and Bhaskaran Swaminathan. 2000. Price Momentum and Trading Volume. Journal of Finance 55: 2017-69. [CrossRef]

Llorente, Guillermo, Roin Michaely, Giden Saar, and Wang Jiang. 2002. Dynamic Volume-Return Relation of Individual Stocks. Review of Financial Studies 15: 1005-47. [CrossRef]

Lo, Andrew W., and Jiang Wang. 2006. Trading Volume: Implications of an Intertemporal Capiral Asset Pricing Model. Journal of Finance 61: 2805-40. [CrossRef]

Ndjadingwe, Emmanuel, and Ishmael Radikoko. 2015. Investigating the Effects of Dividends Pay-out on Stock Prices and Traded Equity Volumes of BSE Listed Firms. International Journal of Innovation and Economic Development 1: 24-37.

Pathirawasam, Chandrapala. 2011. The Relationship between Trading Volume and Stock Returns. Journal of Competitiveness 3: 41-49.

Pisedtasalasai, Anirut, and Abeyratna Gunasekarage. 2007. Causal and Dynamic Relationships among Stock Returns, Return Volatility and Trading Volume: Evidence from Emerging Markets in South-East Asia. Asia-Pacific Financial Markets 14: 277-97. [CrossRef]

Remorov, Rodion. 2014. Stock Price and Trading Volume during Market Crashes. International Journal of Marketing Studies 6: 21-30. [CrossRef]

Rutledge, David J. S. 1984. Trading Volume and Price Variability: New Evidence on the Price Effects of Speculation. In Selected Writings on Futures Markets: Research Directions in Commodity Markets. Edited by Peck Anne E. Chicago: Chicago Board of Trade, pp. 237-51.

Saatccioglu, Kemal, and Laura T. Starks. 1998. The Stock Price-Volume Relationship in Emerging Stock Markets: The Case of Latin America. International Journal of Forecasting 14: 215-25. [CrossRef] 
Safvenblad, Patrik. 2000. Trading Volume and Autocorrelation: Empirical Evidence from the Stockholm Stock Exchange. Journal of Banking and Finance 24: 1275-87. [CrossRef]

Schwert, William. 1989. Why Does Stock Market Volatility Change Over Time? Journal of Finance 44: 1115-55. [CrossRef]

Statman, Meri, Steven Thorley, and Keith Vorkink. 2006. Investor Overconfidence and Trading Volume. Review of Financial Studies 19: 1531-65. [CrossRef]

Sundali, James, and Rachel Croson. 2006. Biases in Casino Betting: The Hot Hand and the Gambler's Fallacy. Judgment and Decision Making 1: 1-12.

Terrell, Dek. 1994. A Test of the Gambler's Fallacy: Evidence from Pari-Mutuel Games. Journal of Risk and Uncertainty 8: 309-17. [CrossRef]

Terrell, Dek. 1998. Biases in Assessments of Probabilities: New Evidence from Greyhound Races. Journal of Risk and Uncertainty 17: 151-66. [CrossRef]

Terrell, Dek, and Amy Farmer. 1996. Optimal Betting and Efficiency in Parimutuel Betting Markets with Information Costs. The Economic Journal 106: 846-68. [CrossRef]

Tran, Quoc T., and Y. Dat Mai. 2015. Stock Market Reaction to Dividend Announcements from a Special Institutional Environment of Vietnamese Stock Market. International Journal of Economics and Finance 7: 50-58. [CrossRef]

Tversky, Aaos, and Daniel Kahneman. 1971. Belief in the Law of Small Numbers. Psychological Bulletin 76: 105-10. [CrossRef]

Tversky, Aaos, and Daniel Kahneman. 1973. Availability: A Heuristic for Judging Frequency and Probability. Cognitive Psychology 4: 207-32. [CrossRef]

Tversky, Aaos, and Daniel Kahneman. 1974. Judgment under Uncertainty: Heuristics and Biases. Science 185: 1124-31. [CrossRef] [PubMed]

Varian, Hal R. 1989. Differences of Opinion in Financial Markets. In Financial Risk: Theory, Evidence and Implications: Proceedings of the 11th Annual Economic Policy Conference of the Federal Reserve Bank of St. Louis. Berlin and Heidelberg: Springer, pp. 3-37.

Verrecchia, Robert E. 1981. On the Relationship between Volume Reaction and Consensus of Investors: Implications for Interpreting Tests of Information Content. Journal of Accounting Research 19: 271-83. [CrossRef]

Westerfield, Randolph. 1977. The Distribution of Common Stock Price Changes: An Application of Transactions Time and Subordinated Stochastic Models. Journal of Financial and Quantitative Analysis 12: 743-65. [CrossRef]

Wu, Xueping. 2002. A Conditional Multifactor Analysis of Return Momentum. Journal of Banking and Finance 26: 1675-96. [CrossRef]

Xu, Peter, Oliver M. Rui, and Sangphill Kim. 2002. Risk Shift Following Dividend Change Announcement: The Role of Trading. Review of Quantitative Finance and Accounting 19: 45-63.

Ying, Charles C. 1966. Stock Market Prices and Volumes of Sales. Econometrica 34: 676-86. [CrossRef]

Ziebart, David A. 1990. The Association between Consensus of Beliefs and Trading Activity Surrounding Earnings Announcements. The Accounting Review 65: 477-88.

Zielonka, Piotr. 2004. Technical Analysis as the Representation of Typical Cognitive Biases. International Review of Financial Analysis 13: 217-25. [CrossRef]

(C) 2017 by the author. Licensee MDPI, Basel, Switzerland. This article is an open access article distributed under the terms and conditions of the Creative Commons Attribution (CC BY) license (http:/ / creativecommons.org/licenses/by/4.0/). 